\title{
The Importance of Literary Texts in Teaching Language in EFL Classes: The Waste Land as an Example
}

\author{
Chnara H. Khdhir, Mariwan N. Hasan \\ English Department, University of Sulaimani, Sulaimani, Iraq \\ Email address: \\ chnara.khdhir@univsul.edu.iq (C. H. Khdhir), mariwan.hasan@univsul.edu.iq (M. N. Hasan)
}

\section{To cite this article:}

Chnara H. Khdhir, Mariwan N. Hasan. The Importance of Literary Texts in Teaching Language in EFL Classes: The Waste Land as an Example. International Journal of Literature and Arts. Vol. 4, No. 1, 2016, pp. 1-6. doi: 10.11648/j.ijla.20160401.11

\begin{abstract}
This study aims to demonstrate how literature can be utilised in teaching language to improve learner's familiarity of English in EFL classes. Researchers intend to study the advancement of literature in the language classes firstly. We will focus on certain reasons that justify its implementation in language teaching, the importance of reading in language improvement, and the style poetry is dealt with in the EFL classes. The Waste Land can be utilised as a tool to improve student's communicative skill in English. The paper will come up with an educational suggestion for EFL teaching based on The Waste Land.
\end{abstract}

Keywords: Language Teaching Through Literary Texts, EFL, The Waste Land

\section{Introduction}

This study intends to demonstrate the significant part of literature as an asset for second language acquisition. Here the attention will be on the utilization that language instructors perhaps make of The Waste Land to offer students some assistance to improve their proficiency in English. Literary texts supply numerous linguistic chances to the language learner and permits the instructor to plan exercises that depend on material fit for empowering more noteworthy hobby and inclusion than numerous other non-scholarly useful writings (Carter and, Long 3). Also Duff and Maley think that the point of these exercises ought to be to concentrate on the structure and substance of the content in question, and to give the boost to communication to happen between the learners among them, and with the instructor (3).

This paper is encircled within the communicative approach to deal with language teaching. This infers that the advancement of informative method ought to be the last point of any language activity. The pertinence of literary texts in this methodology is, from one perspective, that conveys messages. It is a method for correspondence between the writer and the reader. Whereas, writing gives careful consideration to shape, and this helps the learner reflect about language, another guideline and objective of the communicative approach. It is vital that the learners build up their etymological ability by figuring out how to express implications in English, additionally that they build up their informative capability, that will permit them to convey messages, to utilize the language to interface, to speak with other individuals, which is, at last, the essential function of the language. The utilization of literature an instructing instrument is legitimated by the actualities said above, in particular, on the grounds that it furnishes with valid linguistic and social material, and on the grounds that it persuades the learners to cooperate.

The genre selected fits in with the modern tradition and may have never been utilized as a part of the literature as a language educating asset. The Waste Land is all that much sufficient for instructing because of its high academic potential both as respects its content and its structure. The modern thoughts and theory hidden the poem consequence of an amazingly high enthusiasm for learners who might just feel identified with the writer of the poem.

This paper is sheds light on three primary parts. The first one is hypothetical and clarifies the utilization that of writing generally, and of verse specifically, is being made as an asset for second language acquisition. The second part studies the examination of the reasons why the T. S. Eliot's The Waste Land is thought to be appropriate for such an approach.

The final part is useful and gathers various recommendations for classroom exercises to be completed with the poem to improve language learning and literary consciousness. 


\section{The Significance of Literary Texts in Language Teaching}

\subsection{Historical Development}

Literature and Language are firmly related and this is a certainty none can deny. Literature is constituted by language and it speaks to a standout amongst the most repetitive employments of language.

Language and linguistic examination can likewise be utilized to get to writing from the learner's perspective. Brumfit and Carter effectively accentuated the function of literature as "an partner of dialect". This system is in no way, shape or form novel, since literary text has been a generally utilized showing tool as a part of diverse language educating systems. Moreover, here the viewpoint changes giving more importance to the scholarly content as a gem. As a matter of first importance, let us go over the changing part of literature in the convention of second language instructing to end with a record of its present circumstance inside of the communicative methodology (1).

In the sentence structure interpretation technique, literature was the focal part. Literary manuscripts of the target language were perused and deciphered, utilized as samples of good written work furthermore, delineations of the syntactic tenets (Duff and Maley 3). The emphasis of this teaching technique was on structure, on taking in the guidelines of sentence structure and the lexical things as they showed up in the content. There was no scholarly intrigue, nor enthusiasm on substance. After this technique fell in neglect, literary manuscripts additionally went ignored for instructors of second language.

For the basic ways to deal with dialect instructing, writing was ruined as an apparatus, since it spoke to the old convention. The practical notional strategy overlooked writing, since in this system the significance lies on correspondence and they introduce real dialect tests. Literature was not considered either to have an informative capacity or to be legitimate case of language use.

In any case, in the most recent decade or so the enthusiasm for writing as a standout amongst the most profitable dialect showing assets accessible has resuscitated astoundingly (Duff and Maley 1990: 3).

Sanz and Fernández believe this is in consonance with the new streams inside of the open approach that see in perusing writing the ideal acknowledgment of their standards, to be specific creating informative skill, that is instructing learners to convey in the second dialect and bookkeeping for genuine, legitimate informative circumstances.

Literature perusing is, probably, an informative movement and artistic writings are, who could these days deny such thing, credible samples of dialect use. Numerous creators, among them Brumfit and Carter and Lazar reject the thought of the presence of a specific scholarly dialect and case that the dialect utilized as a part of abstract writings is basic language with a high grouping of etymological elements like analogies, metaphors, idyllic lexis, irregular syntactic examples. These are not literature specific since these components likewise show up in conventional dialect use furthermore in nursery rhymes, adages on the other hand attention mottos, just to refer to a couple of illustrations, in any case, in literature these demonstrate a higher rate. We talk in this way, of an artistic utilization of a language.

One could say that there are three primary criteria that legitimize the utilization of literary texts as a second langauge showing instrument (Duff and Maley 6). In the first place, the linguistic paradigm protects that writing ought to be utilized as a part of dialect educating, on the grounds that it furnishes the learner with certifiable, real examples of language, furthermore with genuine specimens of an extensive variety of styles, content sorts and registers. It is critical for none native language learners to be prepared in an assortment of registers, styles and kinds and to have the capacity to observe the capacity of each of them. Sanz and Fernández believe that these diverse signs of dialect are particular linguistically, as well as socially; they all have a social open capacity. This needs to do with the idea of ampleness.

It refers to the way that a message should be etymologically right and situationally proper, as respects its content, as well as its structure.

The methodological comes second in the criterion and relates to the point that a literary manuscript has multiple interpretations, these produce dissimilar attitudes amongst the learners and this leads to actual, encouraged communication with the poem, with the associated learners and with the teacher (Widdowson). Interaction is one of the foundations of the communicative method which protects that it is by interrelating, by collaborating, that the language is learned (Sanz and Fernández). From the methodological opinion, additional aspects that favour the use of literature in the language classes are the vigorous role of the learner and the literary manuscript like the focal place of care.

As per Collie and Slater (3), there are four fundamental reasons which lead a language instructor to utilize writing in the classroom. These are profitable legitimate material, social improvement, language enhancement and individual contribution. Notwithstanding these four primary reasons, comprehensiveness, non-technicality, individual importance, assortment, interest, economy and suggestive force and equivocalness are some different components requiring the utilization of writing as an intense asset in the classroom setting.

\subsection{Why to Use Literary Manuscripts in Teaching Foreign Language Classes}

\subsubsection{Useful Reliable Material}

Literature is a valid material. Most works of writing are not made for the main role of showing a language. Numerous legitimate examples of language, all things considered settings (i. e. travel timetables, city arrangements, shapes, pamphlets, kid's shows, ads, daily paper or magazine articles) are incorporated inside as of late grew course materials. In this way, in a classroom connection, learners are presented to genuine dialect tests of genuine/ genuine like settings. Writing can go about as a valuable supplement to such 
materials, especially when the first "survival" level has been passed. In perusing scholarly messages, in light of the fact that understudies have likewise to adapt to dialect expected for local speakers, they get comfortable with a wide range of phonetic structures, informative capacities and implications.

\subsubsection{Cultural Development}

For some language learners, the perfect approach to expand their comprehension of verbal/nonverbal parts of correspondence in the nation inside which that language is talked - a visit or a broadened stay - is simply not likely. For such learners, abstract works, for example, books, plays, short stories. encourage seeing how correspondence takes place in that nation. Despite the fact that the universe of a novel, play, or short story is a fanciful one, it presents a full and vivid setting in which characters from numerous social/local foundations can be depicted. A reader can find the way the characters in such artistic works see the world outside.

\subsubsection{Language Improvement}

Literary manuscripts give learners an extensive variety of individual lexical or syntactic items.

Students become comfortable with numerous components of the composed language, perusing a generous and contextualized assortment of content. They find out about the grammar and speech elements of sentences, the assortment of conceivable structures, the distinctive methods for interfacing thoughts, which create and enhance their own particular written work aptitudes. Learners likewise turn out to be more gainful and bold when they start to see the extravagance and differing qualities of the language they are attempting to learn and start to make utilization of some of that potential themselves. Along these lines, they enhance their communicative and social richness in the real lavishness, expectation of the valid manuscripts.

\subsubsection{Individual Participation}

Literary texts can be helpful in the language learning procedure attributable to the individual association it encourages in the reader. Once the student examines an abstract content, he starts to study the content. He is drawn into the content. Understanding the implications of lexical things or expressions turns out to be less noteworthy than seeking after the improvement of the story. The current study aims to figure out what happens as occasions develop by means of the peak; he feels near certain characters and shares their passionate reactions. This can have helpful impacts upon the entire dialect learning procedure. At this crossroads, the noticeable quality of the choice of an abstract content in connection to the needs, desires, and intrigues, dialect level of the understudies is obvious. In this procedure, he can remove the personality crisis and form into an outgoing individual.

According to Maley, there are several reasons behind using literary texts in language teaching and he specifies the factors as: universality, non-triviality, personal relevance, Variety, Interest, economy and Suggestive Power as well as Ambiguity. (3)

\subsection{How to Choose Proper Literary Texts in Foreign Language Classes}

While choosing the literary texts to be utilized as a part of language classes, the language educator should consider needs, inspiration, intrigues, social foundation and language level of the students. On the other hand, one main consideration to consider is whether a specific work is ready to uncover the sort of individual inclusion by stirring the learners' advantage and inspiring solid, positive responses from them. Examining an artistic content will probably have a long haul furthermore, important impact upon the learners' phonetic and extra linguistic information when it is important and entertaining. Picking books pertinent to the genuine encounters, feelings, or longs for the learner is of extraordinary significance. Language trouble must be considered also.

On the off chance that the dialect of the abstract work is basic, this may encourage the fathomability of the scholarly content however is not in itself, the most urgent standard. Interest, claim, and importance are additionally conspicuous. Happiness; a crisp knowledge into issues felt to be identified with the heart of individuals' worries; the delight of experiencing one's own particular considerations or circumstances exemplified obviously in a show-stopper; the other, square with joy of seeing those same contemplations, emotions, feelings, or circumstances exhibited by a new point of view: all these are thought processes helping learners to adapt to the etymological impediments that may be considered excessively awesome in less including material (Collie and Slater 6-7).

\subsection{Literary Texts as Themes for Writing}

Finding appropriate material for their written work classes is sometimes troublesome for arrangement instructors since writing has no topic of its own. One advantage of having writing as the perusing item of a structure course is that the readings turn into the topic for arrangements. In an arrangement course whose perusing item is literature, students make inductions, plan their own particular thoughts, and take a glance at content for proof to strengthen speculations. In this manner, they figure out how to think innovatively, openly and basically. Such a preparation helps them in different courses which require consistent thinking, autonomous considering, also, cautious investigation of the content (Spack 719).

\subsection{Why to Use Poetry in Language Teaching}

Among the abstract kinds utilized as a part of language educating, verse is one of continuous appearance. Because of their short length, flawlessly suitable for a solitary classroom lesson, their impossible to miss structure, their trademark linguistic components (uncommon syntactic examples, polysemy of words, similar sounding word usage, and so forth.) poems get to be most loved instruments for dialect instructors. The suggestive character of verse, its symbolism, its speech to sentiments and individual experience make it 
exceptionally fascinating and agreeable for the second dialect learner. Particularly, verse can prompt an attractive inventive expression in the outside dialect and they more often than not incite a solid reaction from the reader which will propel further perusing (Collie and Slater 226).

The significance of verse and its handiness in language classroom lies in the way that verse strays from typical language in that it has some irregular methods for requesting words, or it properties specific, innovative implications to words or joins sounds in a musical, nonconventional manner (phonological, lexical, syntactic, semantic, graphological, and style deviation (Ramsaran 36). The language educator ought to misuse the aberrance of the lovely language with a specific end goal to emerge the dialect attention to the learners towards the path in which dialect can be adjusted or changed to fulfil distinctive communicative purpose.

\subsection{Why to Choose the Waste Land}

McKay stated that' the key to success in using literature in ESL class seems to me to rest in the literary works that are selected' (193). Certainly, The Waste Land offers incredible pedagogical opportunities for its magnificent language and language practice, and its dubious hidden philosophy.

\subsection{The Content of the Waste Land}

From the perspective of a content analysis, the poem demonstrates a progression of components that make it exceptionally intriguing for the language classroom. Above all else, the poem is one of the most important artistic works of the most recent century. Both artistic and socially it checked a defining moment. It tested the built up guidelines and achieved another current: innovation, which attacked all fields of social appearances in writing, as well as in construction modelling or painting. This lyric changed the substance of the twentieth century society (Selby 7). After the Great War, Europe, its fields and its kin were left depleted. The revulsions of the war, the physical, passionate, political and social decimation and bedlam that it deserted rouse The Waste Land. T. S. Eliot, the poet, in the same way as others of his counterparts, was persuaded that the old social and social qualities, standards and convictions had been passed up the war and the new encounters (Selby 7). They were no longer substantial and a sentiment misfortune and of deserting supplanted them. Modernism can be contrasted with youth, on the grounds that in this season of life there are numerous new encounters going on. Readers may feel the verse is telling somewhat their life, the way they feel, the considerations and sentiments. They may relate to the poet and feel he is to some extent or another telling their account of uneasiness in some snippet of their lives; it is important to choose topics with which the students can recognize (McKay 194). The significance and enthusiasm of The Waste Land lies here. Its perusing both makes and requests a high level of individual contribution from the learner. The poem takes into account numerous elucidations, since it shows a progression of legendary and typical parts which are for the reader to translate relying on selfexperience on the structures of the mind and feeling, (Traversi 14), at this, readers are more engaged with poem.

\subsection{The Form of the Waste Land}

It is a long poem; its association is fairly fragmentary. This permits the instructor to outline exercises and arrange term classes at two levels. From one perspective, the person parts of the poem can be utilized for every single lesson, for instance as separated by Eliot, then again he might find an option discontinuity; then again, the poem may be utilized for a few sessions more than maybe a couple weeks. It has the point of preference that it tells a wide range of stories inside of the edge of a more extended story, a sort of "superstory", and this can be abused by adding to various activities that arrangement with every sub-topic and with the general subject.

As Eliot recognizes himself in The Waste Land, it is "a heap of broken images", where voices also, characters succeed each other and superpose. This novel association and representation of experience is exceptionally propelling and will draw in learners in honest to goodness interpreting of informative meaning.

Its uncommon relationship of words (collocations) or the unconventional implications ascribed to a few words or expressions: "April is the cruellest month", "mixing dull roots with spring rain", "winter kept us warm" and so on can be utilized by the educator to have the learner reflect on the way of the remote language and on the diverse purposes that can be accomplished by changing the general word request, adjusting the normal significance of a word or developing new mixes of two lexical.

Another motivation behind why we worked with The Waste Land is that it is a modern work and in this way, its language is advanced and justifiable. The mix of diverse languages (Latin, Italian, German, Sanskrit and French) that show up in the poem is likewise exceptionally fascinating and engaging for the learners. The educator can make them reflect about the motivation behind utilizing those diverse languages and the impact accomplished by this, helping them, along these lines, to create their insight into the standards of social use, together with the guidelines of punctuation.

One knows about the linguistic and theoretical difficulty of the poem. The way that there are complicated fields, that the learners can succeed, is testing and rousing and it is a further motivating force to read and take a glimpse at the poem. It is fundamental to clarify that specialists show inclination for valid, non-simplified writings, since they are a great deal more important from the linguistic perspective, in light of the fact that they give real language in context and natural stimuli, by the investigation content, that prompt examination of language (Brumfit and Carter 15). Grellet asserts that the difficulty is not on the content itself yet on the activities that are required of the students (7).

Literature can enhance reading comprehension, all things considered, on the grounds that reading proficiency lays on the connection in the middle of reader and author, 
cooperation intervened by the content (McKay 192). The all the more rousing and agreeable the content, the more serious, genuine and capable the connection will be (Brumfit and Carter 15). At the point when perusing lyric, learners are conveying, disentangling implications and reflecting on vernacular and correspondence methodologies in the foreign language, this is an "essential element in the improvement of tongue learning capacities" (Brumfitand Carter 14). Cassany goes somewhat further and asserts that spurring so as to peruse helps create composing capacities their own particular inventive composition and by furnishing them with samples of language utilisation.

Proposal of the Activities to be Utilised in The Waste Land

These exercises are thought to be some managing framework to work with The Waste Land as a language educating asset. They are tended to intermediate advanced learners of English at University level. Pursuing Maley our activities will be separated into four primary segments: reacting, examining, composing, and further analysis.

Responding: this is what customarily has been called preperusing exercise:

1. Think with an collaborator of a circumstance where you felt miserable, or even destroyed. This may offer ascent to a bunch of reactions, for instance when left by the cherished individual, when somebody in the family kicked the bucket, or when coming up short in an exam.

2. Finding from the title. What do you think the poem is about? Work in groups. Here we may expect answers, for example, a war, a pestilence that slaughtered numerous in a little area, annihilation of fields or harvests by the foe, relinquishment of the family, destitution due to shortage of rain and dried yield.

3. Consider things that may squander an area, or a man. Conceptualizing with the entire class, the educator records on the writing board. Students may think of words for example, misuse, floods, draft, diligent work, anxiety, and strain.

4. With your partner, think about a general connection out of which such a verse could have come to be: nation, age, individual circumstance of the writer, financial and political happenings, and so forth. For instance, learners may think about a family in the Middle Ages, whose fields have been crushed by a flood and who are starving. The entire province what's more, nation, for instance England, is experiencing a scourge because of the floods, what's more, the artist, the child of the poor family chooses to compose his story.

With these starting exercises, the instructor will smooth the way of the perusing activity what's more, aides the learners to what they will be managing the following days. It is essential the learners foresee what will come and that they have some past thought of what they are going to peruse. This is a critical technique in language learning, as well as in communication, according to the view of Maingay.

5 . Read the poem in advance.

Examining: the exercises in this area will lead to a more profound investigation of the poem both as form and structure are concerned: neighbourhood and worldwide vision.

Common Conception Queries.
6. What does the poem deal with? Where is it set? What is the focal subject of each of the five parts of the poem? Here the teacher ought to give the learners some kind of background knowledge about the general age of the poem and the occasions that were occurring in Europe around then. Giving background information to the learners is a decent enhance their comprehension of the content, and in this manner, improve the pedagogical impact of the exercises implemented (Lazar 38). There exists a few methods for displaying this data, as a mini-lecture, as a perusing or listening understanding or as an examination venture for understudies to execute (Lazar 38).

Internal Investigation.

7. The The Waste Land has the idiosyncrasy, as seen, of being split up into a wide range of thematical and auxiliary parts. With an accomplice recognize those distinctive pieces and think about a descriptor or expression that best defines that specific part. The pieces they may distinguish can be: The entombment of the demise, the debilitated Fisher King, the moderate, tragic going of the seasons and the coming of the icy winter, and so on. The words or expressions used to depict these pieces can be passing, destruction, trouble, depression, coldness.

8a) the entire class, think about a few expressions or descriptive words that define the emotion the lyric incites in you.

8b) War, discontinuity, passing, devastation, misery, decimation, dejection are some of the emotions the ballad endeavors to emerge in the peruser. Find with your accomplice the entries, allegories or implications in the sonnet that for the most part incite those sentiments in you and the ones you remarked on before in $8 \mathrm{a}$ ), or the entries the artist expected to incite you those said emotions.

8c) Try to fi nd, with the utilization of a lexicon, the contrary energies of the words you used to defi ne the emotions you got when perusing The Waste Land.

With these activities, we utilize the repetitive fracture of the lyric and the rehashed suggestions to death and devastation to build up the lexical ability of our understudies. Vocabulary activities base here on sentiments of pity and dejection which will, doubtlessly, make the learner connect in the classroom and in the gathering.

9a) Look deliberately at the first piece of the poem, "The burial of the dead" and attempt to delimit the principle topics. Hint: think about the intermittent thought of death and devastation

What is more, consider the verse: "mixing memory and desire" (LL. 2-3). Work in pairs.

They may pinpoint as intermittent topics of the first part the accompanying: apprehension of passing, be that as it may, acknowledgment of its vicinity in present day life, life under the earth, trust in the future, custom, profound devastation.

9b) Find the topics you have recently discussed in the remaining areas of the poem furthermore, endeavour to see where they find in their solidarity. Learners might find Tiresias as the person who unites the poem, each subject comes down to this legendary character. 
This activity is planned to direct students towards a further comprehension of The Waste Land.

10. Round every single consistent verb that you find and underline sporadic ones. Build up the strained they are in (straightforward past, present immaculate, restrictive, and so forth.) and attempt to decide their capacity. Do likewise with the modal verbs you face in your reading.

This is the practical aspect of grammar.

11. We have as of now discussed the fragmentary structure of the sonnet, there we can see diverse types of telling a story: portrayal, portrayal, dialog; attempt to recognize them in The Waste Land. Would you be able to additionally think about an informative reason for the utilization of each of them in the solid circumstance?

12. As it is obvious, in the poem there are a few dialogues. With a partner work to change these into periodic, colloquial and modern English.

13. Work on reciting in loud a few stanzas of the poem in little groups. What do you notice about the mood, speed, pitch?

14. Think with an accomplice of things that make you feel tragic and that make you startled.

Record them in a list and compose basic sentences with those words or expressions.

Learners may record things, for example, war, neediness, viciousness, misuse, or depression.

Writing (Composing).

This area bases on the thought that through reading composing capacities can likewise move forward. It is imperative that we assist our understudies with developing their composition abilities in the remote language.

15. Compose a short poem, of 10 lines only, where you express you apprehensions and pity. Use the sentences and the words recorded with your accomplice. Work alone.

16. Pick ten words from the ballad that need to do with trust later on and use them to compose a short content with them with the title Hope for what's to come.

17a) What do you think the poet resembled? With a partner list a progression of attributes you think he may have had, both physically, you may even draw him, and rationally. Consider where he may have been conceived, what his occupation may have been, aside from composing verse, or whether he had a crew.

17b) Then, imagine and compose a life story for the creator.

The rundown of exercises that could be incorporated into this segment is colossal. We can think of selecting a word frame the sonnet, expound a semantic family and make a ballad out of them, finishing parts of the sonnet, reshaping the lyric, compose a commentator of the poem.

\section{Conclusion}

The use of literary texts helps students attain a native-like competence in English, express their views in good English, comprehend the characteristics of modern English, familiarize themselves of how the English linguistic system is utilised for communication, realise how idiomatic expressions are utilised, speak obviously, exactly, and briefly, and become more capable in English, and become inventive, critical, and analytical learners. Moreover, literature can open horizons of likelihood, permitting students to raise queries, deduce, relate, and discover. So, literature provides students with an exceptionally rich basis of reliable material over an extensive range of lists. If students can gain access to this material by increasing literary skill, then they can efficiently adopt the language at a high level. In particular, for students with verbal / linguistic intellect, the language instructor's using literature in a foreign language class works for creating an extremely inspiring, amusing and lively lesson. Literature is not only an instrument for improving the written and oral abilities of the students in the target language but also is a window opening into the culture of the target language, building up a cultural competence in students.

\section{References}

[1] Collie, J. and S. Slater. Literature in the Language Classroom: A Resource Book of Ideas and Activities. Cambridge: CUP, 1990.

[2] Grellete, F.. Developing Reading Skills. Cambridge: Cambridge University Press, 1981.

[3] Lazar, G.. Literature and Language Teaching. Cambridge: Cambridge University Press, 1993.

[4] Lu, Fei-Pai. TS Eliot: the Dialectical Structure of his Theory of Poetry. University of Chicago Press, 1966.

[5] Maingay, S.. Making Sense of Reading. Hong Kong: Nelson Harrap, 1983.

[6] McKay, S.. "Literature in the ESL Classroom" Literature and Language Teaching.

[7] Ed. C. J. Brumfit and R. A. Carter. Oxford: Oxford University Press, 1986, 191-198.

[8] Maley, A. "Down from the Pedestal: Literature as Resource" in Literature and the Learner: Methodological Approaches. Cambridge: Modern English Publications, 1989.

[9] Spack, R. "Literature, Reading, Writing, and ESL: Bridging the Gaps" in TESOL Quarterly. Vol 19, No. 4, 1985, 703-721.

[10] Williamson, George. A Reader's Guide to T. S Eliot: A Poemby-Poem Analysis. Syracuse University Press, 1998. 